\title{
Design and study of a microstrip slot antenna operating at 2.8/3.1/3.6/4.7/5.4 GHz
}

\author{
Angel Lozada ${ }^{1 *}$, Andrés Piedrahita ${ }^{2}$, Gloria Russi \\ ${ }^{1}$ Electronic Engineering, Faculty of Engineering, Central Unit of the Valley of Cauca, Tuluá, Colombia. \\ ${ }^{2}$ Informatic Engineering, Faculty of Engineering, Central Unit of the Valley of Cauca, Tuluá, Colombia.
}

\begin{abstract}
A novel design of a multi band microstrip antenna is presented in this work. The double modified U slots planar patch antenna is designed, simulated and fabricated to operate at $2.8 \mathrm{GHz}$ (between 2.794 to $2.846 \mathrm{GHz}$ ), at $3.1 \mathrm{GHz}$ (between 3.145 to $3.196 \mathrm{GHz}$ ), at $3.6 \mathrm{GHz}$ (between 3.56 to $3.3 .644 \mathrm{GHz}$ ), at $4.7 \mathrm{GHz}$ (between 4.684 to $4.772 \mathrm{GHz}$ ) and at $5.4 \mathrm{GHz}$ (between 5.423 to $5.526 \mathrm{GHz}$ ) for WiMAX/WLAN applications. One of the main challenges was keeping a low profile and low cost substrate $(1.2 \mathrm{~mm}$ and FR4 respectively) with penta-band frequency response without scarifying these characteristics. Each resonant frequency is accomplished by modifying each $U$ slot and patch radiator itself. Simulations had been conducted using HFSS software and measured parameters such as reflection coefficient (S11 parameter) was performed with a vector network analyzer. Measured results confirm simulated results that the antenna could work within mentioned frequencies. Parametric study was conducted in order to study the effect of slots variation over the design.
\end{abstract}

\section{Introduction}

As a result of development of wireless and satellite communication systems, came out the miniaturization of electronic components and therefore the appearance of microstrip technology and its antennas [1]-[4]. These miniaturization in telecommunications has become more evident during the last 35 years impulsed by low profile devices such as smartphones [5], radio frequency identification systems (RIFD) [6], wearable devices [7], and so on; reason why studying, designing and fabricating microstrip antennas (MSA) still receive attention by researchers around the world. Part of this attention recalls to overcome MSA disadvantages such as low gain, narrow bandwidth and so on; and improve its advantages such as low profile, low cost, capable to work at multi-frequency bands, among other characteristics; enabling these structures to be applied on current wireless communication system.

Multiband microstrip antennas are required because current and future devices must be able to communicate each other through different standards, which mean different frequencies band [8], also the antennas used at base stations use array microstrip antenna to deploy telecommunications networks, satellite communication antennas, along with other applications. In order to achieve multi-frequency response several techniques have been applied such as electromagnetic band gap structure (EBG) [9], ring resonator, defected ground structure antenna (DGS) [10], multilayer antenna, reconfigurable antennas [11], slots antennas [12], etc. Among these variety of designs, slot antennas offer several advantages such as keeping a low profile structure, single designs (which makes available for mass fabrication), bandwidth improvements, multifrequency response along other antenna improvements. But within slots antenna technique there are options designs to achieve researcher's goal. Some of these options are design the patch radiator with alphabet letter shape such as, L shape [13], S shape [6], F shape [14] and U shape [15]-[17] among others. In this paper, a modified double $U$ slot planar microstrip antenna is designed, simulated and fabricated to operate at 2.8/3.1/3.6/4.7/5.4 GHz for wireless communication such as WiMAX/WLAN applications.

\section{Antenna design}

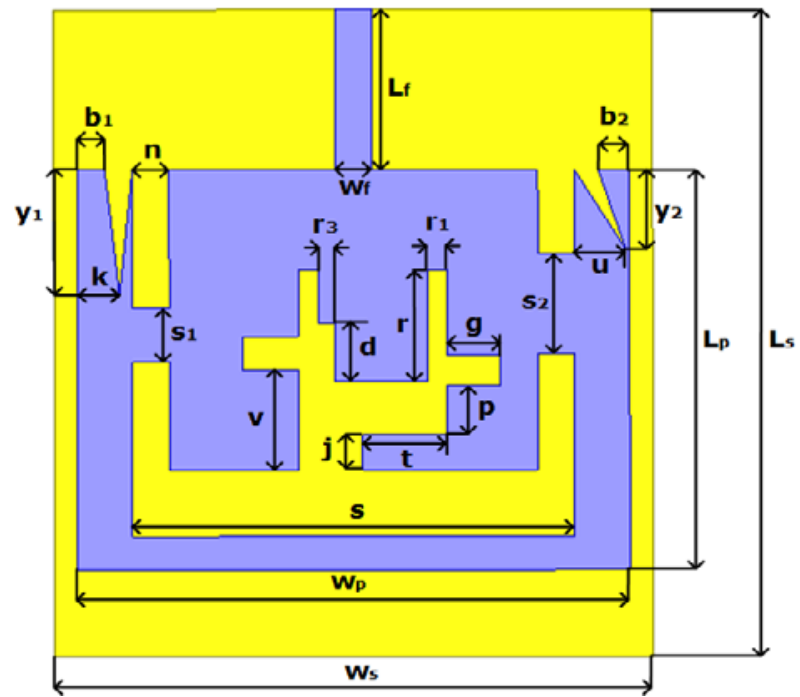

Fig. 1 Antenna Design Parameters

\footnotetext{
* Corresponding author: alozada@uceva.edu.co
} 
The geometry of the proposed antenna is shown in Fig. 1. The antenna is designed and simulated on a FR4 substrate with relative permittivity $\varepsilon_{\mathrm{r}}=4.4$; the substrate is easy to get in domestic market and also less expensive than other used antenna substrates for high-frequency applications, with a thickness $\mathrm{h}=1.2 \mathrm{~mm}$, and a loss tangent $\delta=0.02$ using HFSSv17.2 which is based on Finite Element Method (FEM), the rest of parameters are summarized in Table 1and Table 2.

\begin{tabular}{|c|c|c|c|}
\multicolumn{1}{|c}{ Table 1 Parameters Design } \\
\hline Parameter & $\begin{array}{c}\text { Value } \\
(\mathbf{m m})\end{array}$ & Parameter & $\begin{array}{c}\text { Value } \\
(\mathbf{m m})\end{array}$ \\
\hline Ls & 38.8 & $\mathrm{n}$ & 2 \\
\hline $\mathrm{Ws}$ & 32.5 & $\mathrm{k}$ & 2.3 \\
\hline $\mathrm{h}$ & 1.2 & $\mathrm{~s} 1$ & 3.2 \\
\hline Lp & 24 & $\mathrm{~s}$ & 24 \\
\hline Wp & 30 & $\mathrm{~s} 2$ & 6 \\
\hline Wf & 2 & $\mathrm{~b} 2$ & 1.7 \\
\hline Lf & 9.6 & $\mathrm{y} 2$ & 4.8 \\
\hline $\mathrm{b} 1$ & 1.5 & $\mathrm{u}$ & 2.8 \\
\hline $\mathrm{y} 1$ & 5.5 & $\mathrm{r} 2$ & 0.9 \\
\hline
\end{tabular}

Table 2 Parameters Design

\begin{tabular}{|c|c|}
\hline Parameter & $\begin{array}{c}\text { Value } \\
\text { (mm) }\end{array}$ \\
\hline $\mathrm{d}$ & 3.5 \\
\hline $\mathrm{v}$ & 6 \\
\hline $\mathrm{j}$ & 2.1 \\
\hline $\mathrm{t}$ & 4.6 \\
\hline $\mathrm{p}$ & 3 \\
\hline $\mathrm{g}$ & 2.9 \\
\hline $\mathrm{r} 3$ & 6.7 \\
\hline $\mathrm{r} 2$ & 1.1 \\
\hline
\end{tabular}

Based on [15]-[20], the U slot technique offers the opportunity to get multi-frequency operation in the same way as the slots allow to add one or more resonance frequency or shift them to desired ones keeping a low profile antenna, however most of those designs are fed by coaxial connector and either patch radiator or slots are no modified in deed. Moreover, other designs [21][23] shows U slots patch antenna feeding by stripline getting compact design and multi-frequency response. For this reason the mentioned technique is used to get multiband operation in current research.

\section{Simulation results}

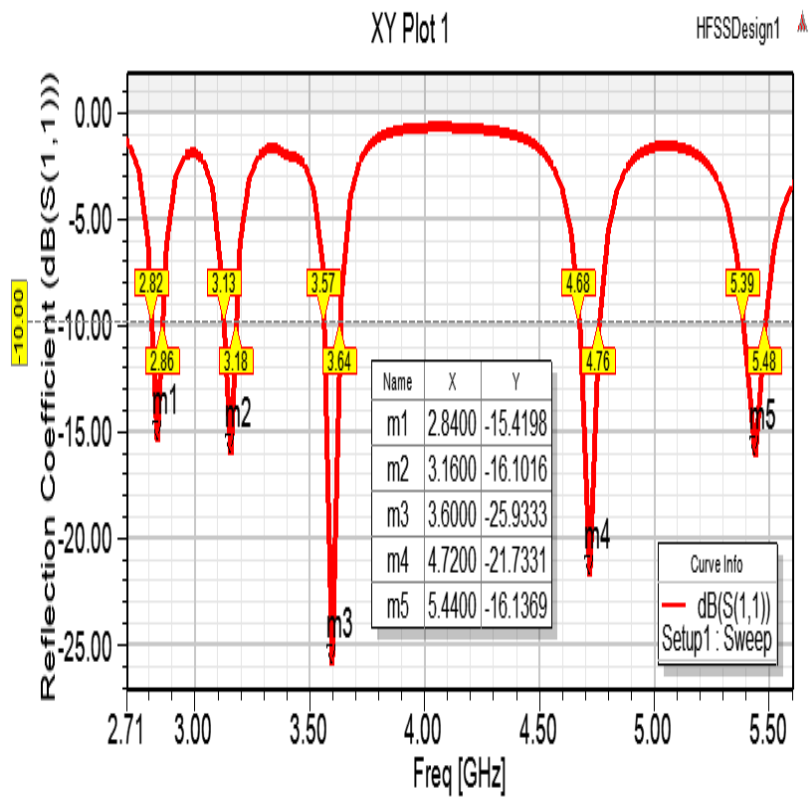

Fig. 2 Reflection Coefficient (S11 Parameter)

Based on reflection coefficient results (S11 parameter curve) of Fig. 2, it is emphasized that at the $1^{\text {st }}$ frequency band of $2.8 \mathrm{GHz}$ the resulting impedance bandwidth is going from 2.817 to $2.863 \mathrm{GHz}$, getting the lower reflection coefficient of $-15.4198 \mathrm{~dB}$ at $2.84 \mathrm{GHz}$, at $2^{\text {nd }}$ frequency band of $3.1 \mathrm{GHz}$ the impedance bandwidth is going from 3.131 to $3.184 \mathrm{GHz}$ with the lower reflection coefficient of $-16.1016 \mathrm{~dB}$ at $3.16 \mathrm{GHz}$, at the $3^{\text {rd }}$ frequency band of $3.6 \mathrm{GHz}$ the impedance bandwidth is going from 3.565 to $3.636 \mathrm{GHz}$ with the lower reflection coefficient of $-25.9333 \mathrm{~dB}$ at $3.6 \mathrm{GHz}$, at the $4^{\text {th }}$ frequency band of $4.7 \mathrm{GHz}$ the impedance bandwidth is going from 4.677 to $4.76 \mathrm{GHz}$ with the lower reflection coefficient of $-21.7331 \mathrm{~dB}$ at $4.72 \mathrm{GHz}$, and at the $5^{\text {th }}$ frequency band of $5.4 \mathrm{GHz}$ the impedance bandwidth is going from 5.389 to $5.483 \mathrm{GHz}$ with the lower reflection coefficient of $-16.1369 \mathrm{~dB}$ at $5.44 \mathrm{GHz}$ to operate for WiMAX and WLAN applications.

In order to further study the penta-band operation properties of the proposed antenna, surface current distributions $(\mathrm{A} / \mathrm{m})$ of the whole antenna at frequencies of 6 (solution frequency), 2.8, 3.1, 3.6, 4.7 and $5.4 \mathrm{GHz}$ are given in Fig. 4-9. 


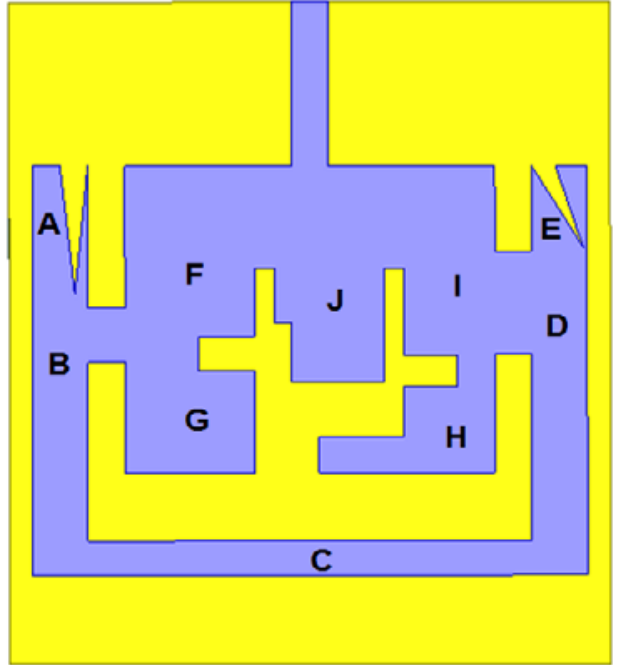

Fig. 3 Antenna Regions

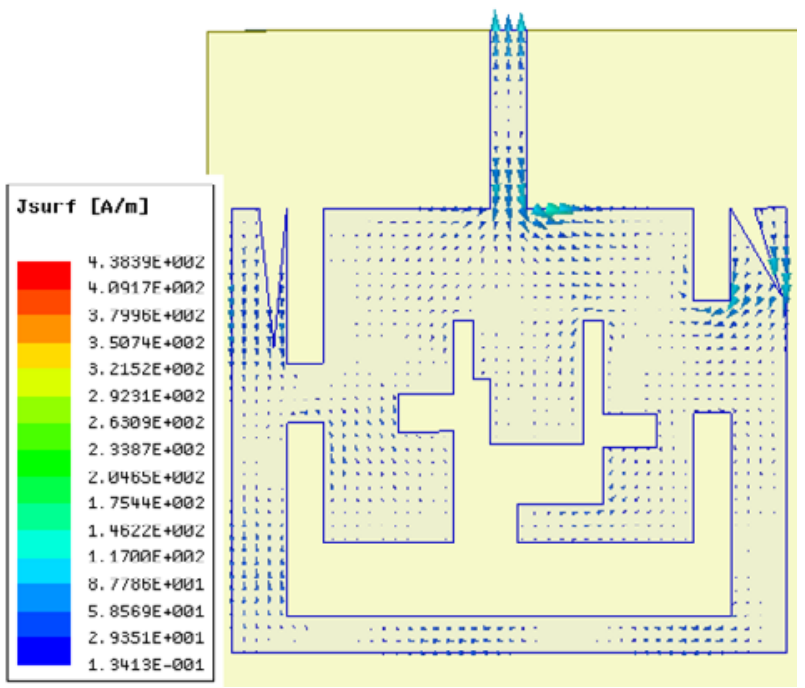

Fig. 4 Vector of Surface Current Density at $6 \mathrm{GHz}$

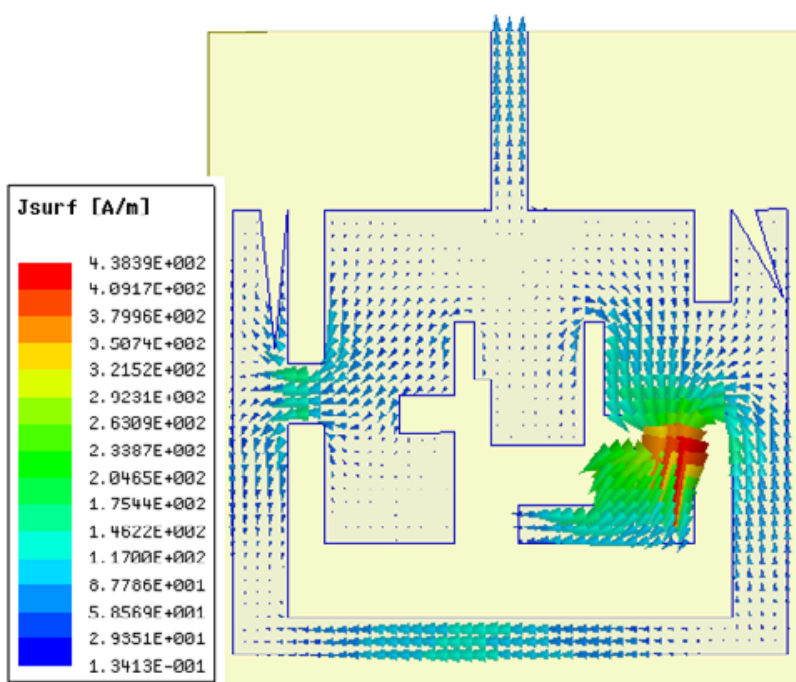

Fig. 5 Vector of Surface Current Density at $2.84 \mathrm{GHz}$

It can be clearly seen from these figures that the current distributions are different in all frequencies. The antenna has been divided in several regions $(\mathrm{A} \sim \mathrm{J})$ as is shown in Fig. 3 for better understanding on current density paths.

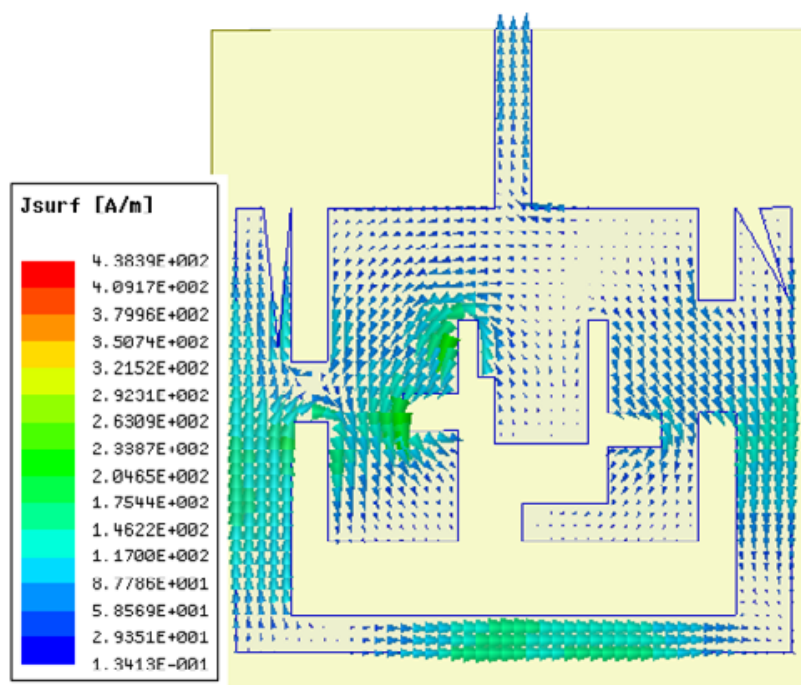

Fig. 6 Vector of Surface Current Density at $3.16 \mathrm{GHz}$

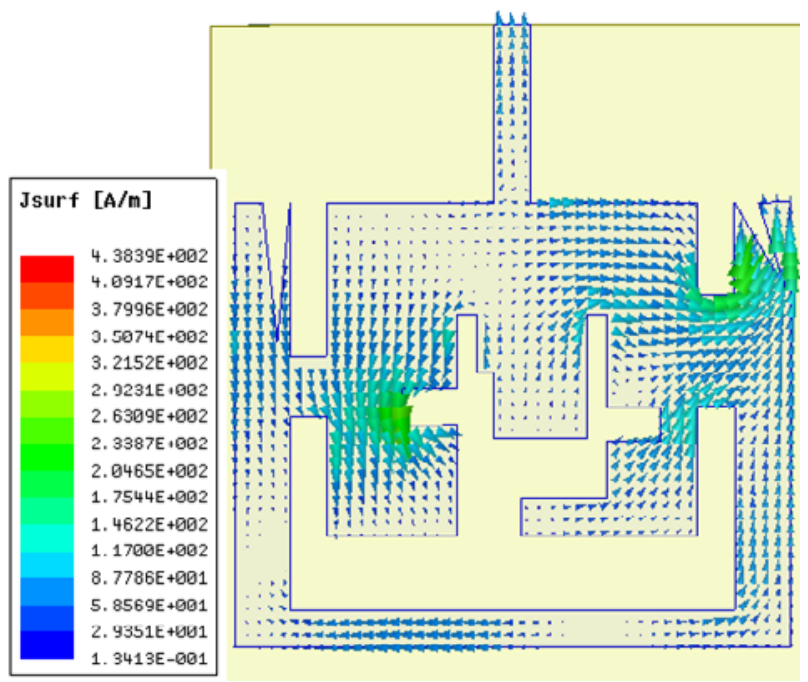

Fig. 7 Vector of Surface Current Density at $3.6 \mathrm{GHz}$

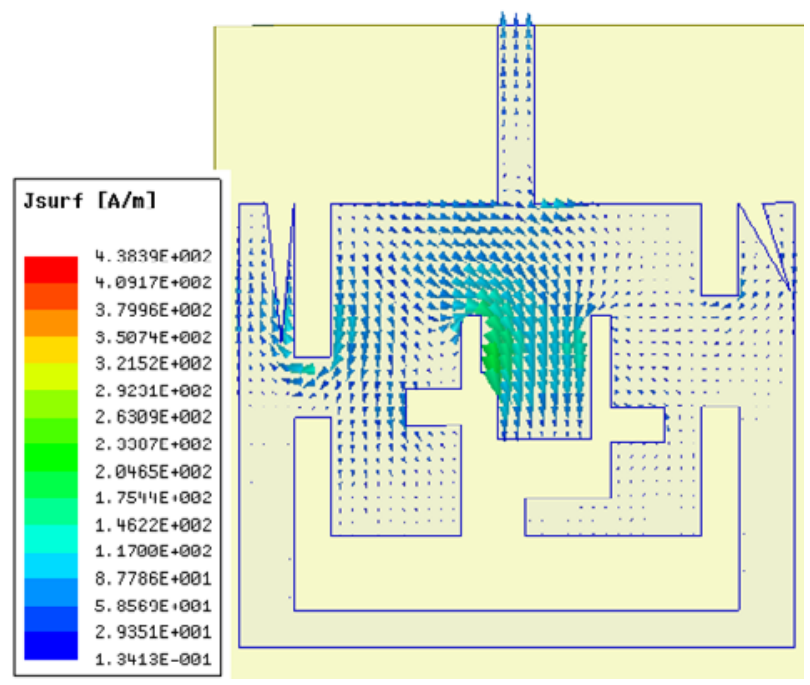

Fig. 8 Vector of Surface Current Density at $4.72 \mathrm{GHz}$ 
In Fig. 4 for instance, the current has a very low flow and magnitude, which means that the patch radiator is not excited at this frequency as is it was expected. But, when the antenna operates at $2.8 \mathrm{GHz}$ it was noticed that the current flows from $\mathrm{I}$ and $\mathrm{D}$ to $\mathrm{H}$ region where is mainly concentrated having the strongest magnitude, also is possible to observe a moderate current density flowing from $\mathrm{F}$ to $\mathrm{B}$ region and from right to left of $\mathrm{C}$ region as is shown in Fig. 5. This clearly indicates the importance of the slots defined by $g, p, s_{2}$ and $t$ parameters on the proposed antenna resonance response.

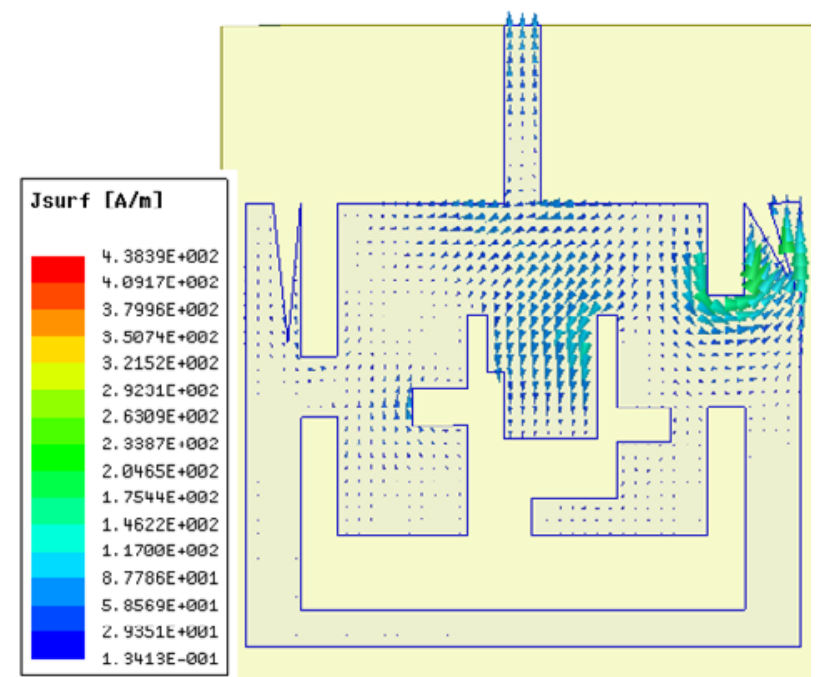

Fig. 9 Vector of Surface Current Density at $5.44 \mathrm{GHz}$

Fig. 6 shows that the current has uniform distribution at $\mathrm{B}, \mathrm{C}, \mathrm{D}, \mathrm{F}$ and $\mathrm{G}$ regions. The current paths flows from upper to lower side of $B$ region, from left to right side of $\mathrm{C}$ region, from lower to upper side of $\mathrm{D}$ region and from $F$ to $G$ region, acting these areas as the resonator for the antenna at $3.6 \mathrm{GHz}$. At $3.6 \mathrm{GHz}$ the current is flowing from $\mathrm{I}, \mathrm{H}$ and $\mathrm{D}$ regions to $\mathrm{E}$ region, also from $\mathrm{F}$ to $\mathrm{G}$ region, making possible to observed the highest current magnitude at $\mathrm{E}$ and $\mathrm{G}$ regions and weak magnitude at $\mathrm{A}, \mathrm{B}$ and $\mathrm{C}$ regions, making $\mathrm{E}$ and $\mathrm{G}$ regions antenna resonate at mentioned band as is shown Fig. 7 which makes the antenna resonate at this frequency.

Fig. 8 shows that the surface current is going from $\mathrm{F}$ to $\mathrm{J}$ region with highest magnitude and concentration at $\mathrm{J}$ region which mean this area is excited and resonate at 4.7 GHz. The J and E regions acts as resonator at 5.4 $\mathrm{GHz}$ as the flow path of surface current is going from I to $\mathrm{E}$ region and from upper side to lower side of $\mathrm{J}$ region, concentrating the highest density and magnitude at mentioned frequency as is shown in Fig. 9.

Controlling the reactance inductive and reactance capacitive contributions of each slot it is possible to do by modifying width, length and position of these structures, which mean that currents path is also modified. Therefore, resonance frequencies can be controlled towards higher and or lower ones.

Introducing slots on the antenna patch modified the current path and so can be used to generate and multiple resonance frequencies band, for WiMAX and WLAN applications.
The gain radiation pattern at solution frequency is shows in Fig. 10. Maximum gain occur at $\varphi=190$ and $\varphi$ $=360$ degrees.

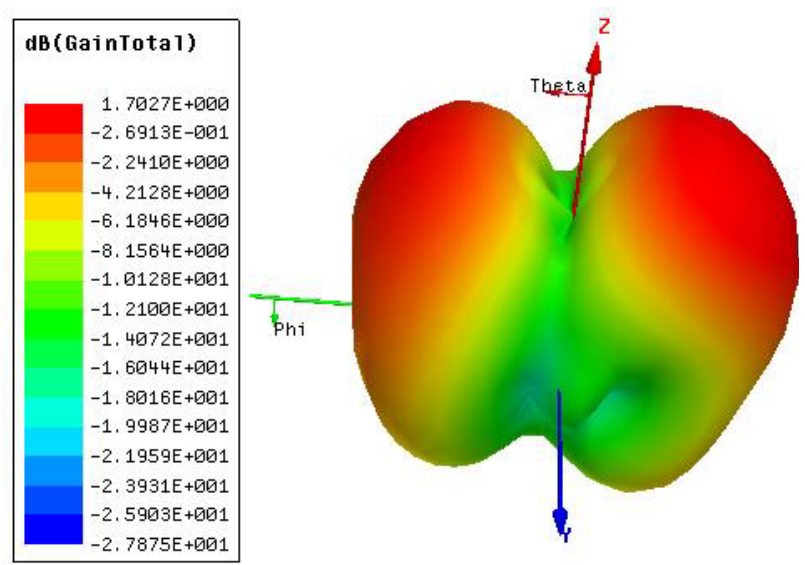

Fig. 10 Gain-Radiation Pattern

\section{Parametric Study}

Parametric study of planar patch microstrip antenna is conducted by varying the width, length and position of slots antenna to understand how it does affects these variations over the resonance frequencies, impedance bandwidth and reflection coefficient values

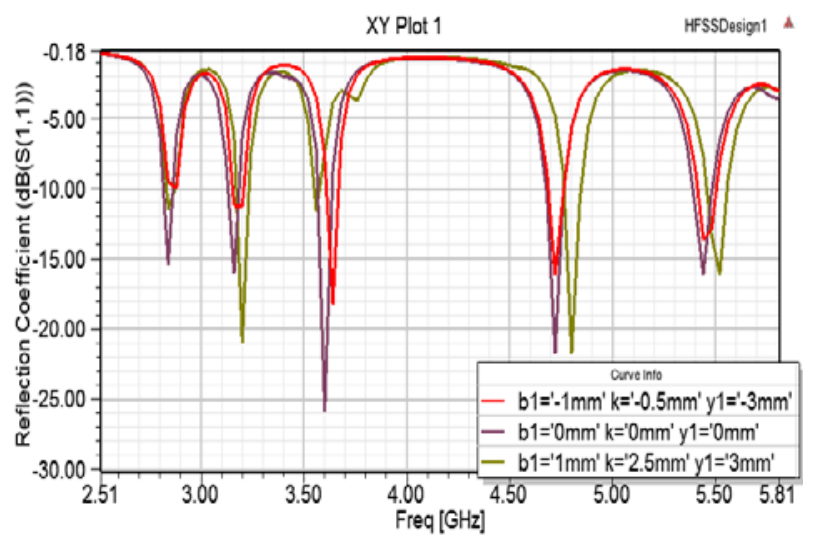

Fig. 11 Parameters b1, k and y1.

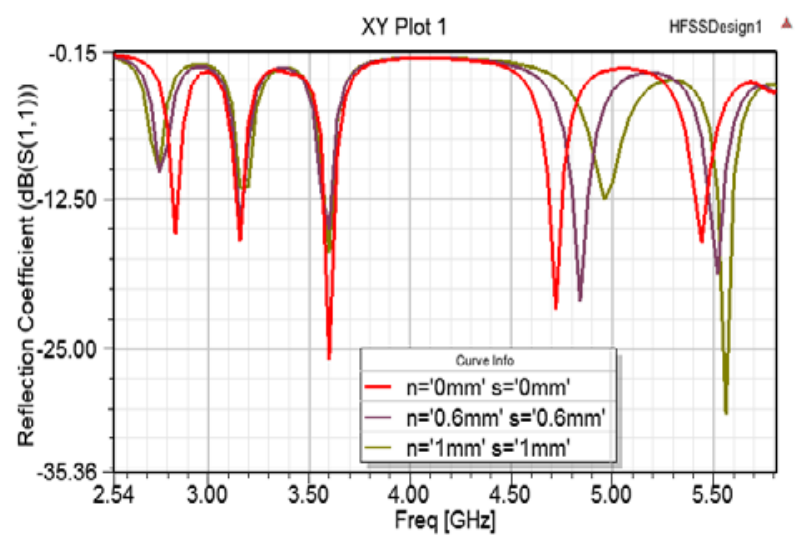

Fig. 12 Parameters $n$ and s.

As it can be seen from Fig. 11 it is possible to study the effects of the slot variations defined by parameters $b 1, k$ and $y 1$. 


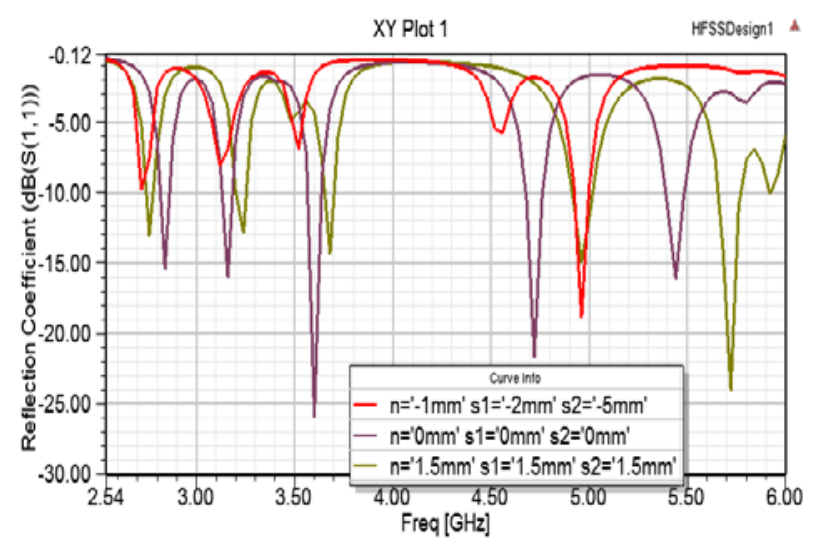

Fig. 13 Parameters n, s1 and s2

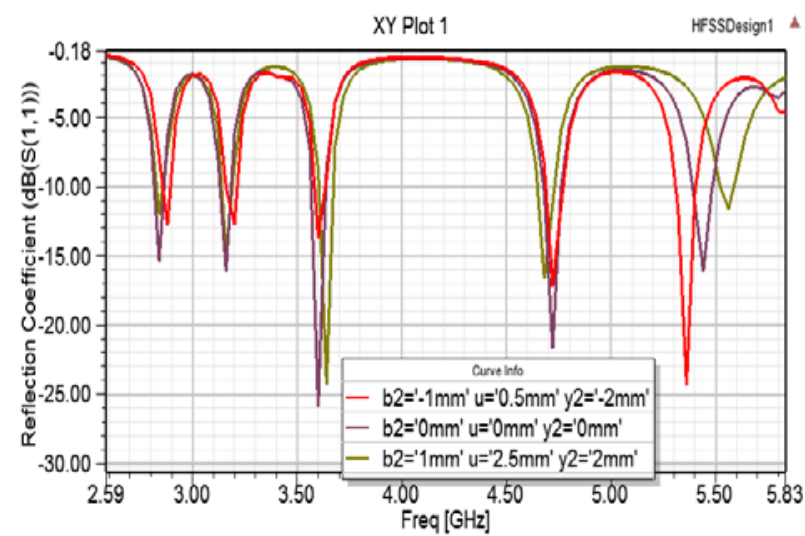

Fig. 14 Parameters b2, $u$ and $y 2$

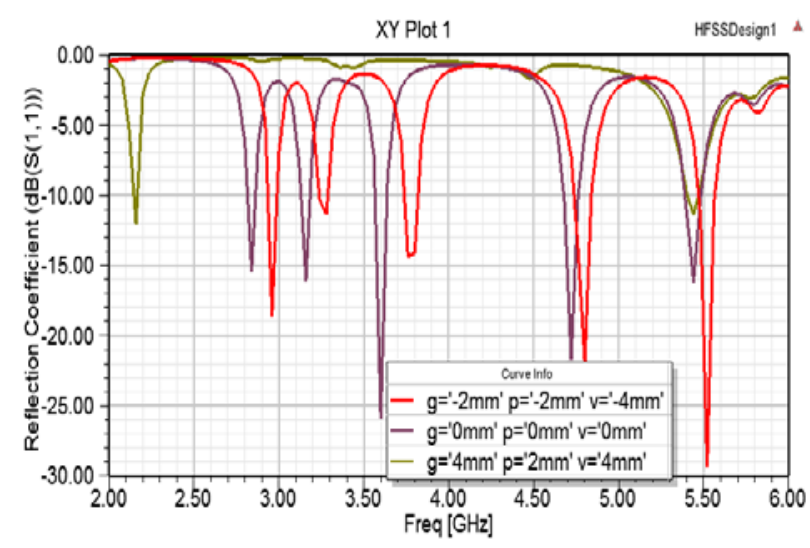

Fig. 15 Parameters $g, p$ and $v$

When mentioned parameters decrease, the reflection coefficient values for all frequencies increase compare with same parameters without modifications, and the $1^{\text {st }}$ frequency is suppressed; but when the parameters increase their dimensions is possible to observe that the $4^{\text {th }}$ and $5^{\text {th }}$ resonant frequencies are moved toward higher ones and $1^{\text {st }}$ and $3^{\text {rd }}$ frequencies have higher reflection coefficient values. It is also possible to observe that at $2^{\text {nd }}, 4^{\text {th }}$ and $5^{\text {th }}$ frequency the reflection coefficient values are lower or equal than without modifications.

As either parameters increase or decrease, the impedance bandwidth shown in most cases a decrement. When parameters $n$ and $s$ increase their dimensions from 0 to 0.6 and then to $1 \mathrm{~mm}$, the $4^{\text {th }}$ and $5^{\text {th }}$ frequency changes toward higher ones, also is possible to evidence that the $1^{\text {st }}, 2^{\text {nd }}, 3^{\text {rd }}$ and $4^{\text {th }}$ frequencies increase their reflection coefficient values suppressing the $1^{\text {st }}$ frequency band as is shown in Fig. 12.

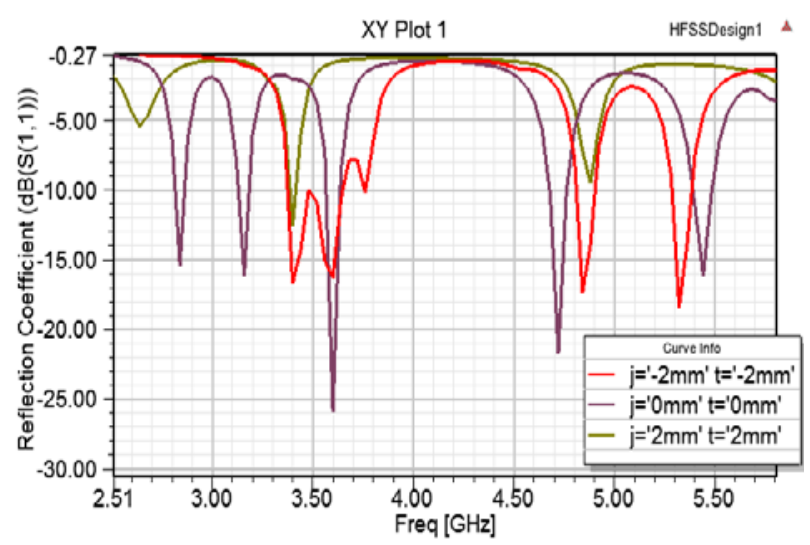

Fig. 16 Parameters $j$ and $t$

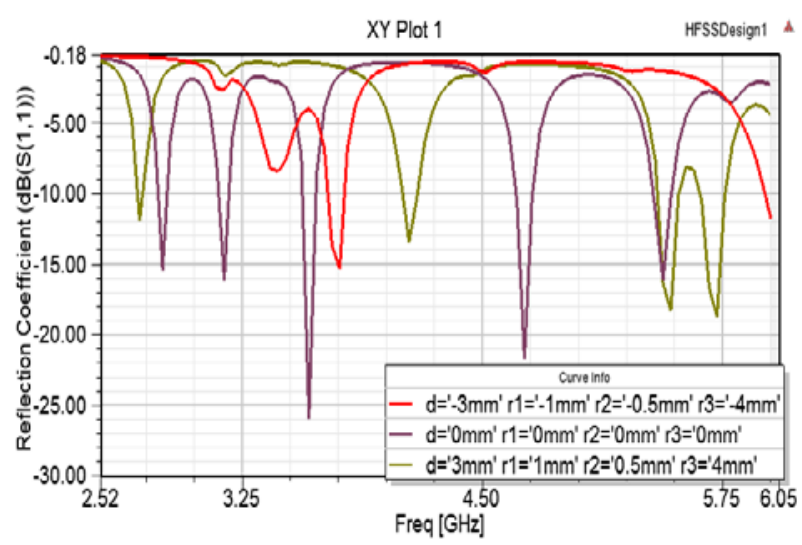

Fig. 17 Parameters d, r1, r2 and r3.

Fig. 13 shows the results of variation parameters of $n$, $s 1$ and $s 2$. When the slot parameters decrease, it shows the suppression of frequencies $1^{\text {st }}$ to $4^{\text {th }}$ (return loss greater than $-10 \mathrm{~B}$ ) and the $5^{\text {th }}$ frequency is shifted to 4.9 $\mathrm{GHz}$, but when slots dimension increase the resonating frequency is shift to higher frequency band (from $2^{\text {nd }}$ to $5^{\text {th }}$ frequency band) but the $1^{\text {st }}$ frequency changes to lower resonance frequency).

The effects of slot parameters defined by $b 2, u$ and $y 2$ are simulated as is shown in Fig. 14. Decreasing slots dimension defined by the mentioned parameters are reflected by the increment of reflection coefficient values for $1^{\text {st }}$ to $4^{\text {th }}$ frequency band and decrement and shifting to lower resonating of $5^{\text {th }}$ frequency band, but the increment of slot dimension mean an increment of reflection coefficient for all frequencies.

When slot dimension defined by $g, p$ and $v$ decreases the antenna exhibit a shift to higher frequencies for the five bands, however when variations include the increment of slot dimensions the antenna resonate at two bands at $2.2 \mathrm{GHz}$ and $5.4 \mathrm{GHz}$ band as the other three frequencies are suppressed at all as is shown in the Fig. 15.

As Fig. 16 shows, there is a shift toward to higher resonance frequencies when parameters $\mathrm{g}, \mathrm{p}$ and $\mathrm{v}$ decrease their values and the antenna become a dual band antenna when mentioned parameters decrease their values suppressing the other three frequencies band. 
A suppression of four frequencies is shown in Fig. 17 when the parameters $d, r_{1}, r_{2}$ and $r_{3}$ present a decrement of their dimensions making the antenna resonate at only one frequency band $(3.7 \mathrm{GHz})$ suppressing the other four; but when parameters increase their values, the antenna resonate at four frequencies. It can be also observed a remarkable difference between parameters variations results, indicating a highly sensitivity of mentioned parameters to these variations.

\section{Fabrication and Measurement}

The antenna was made using the LPKF ProtoMat S103 circuit board plotter for producing PCB/antenna prototypes. Once the antenna was fabricated (top and bottom view of fabricated antenna are shown in Fig. 18, the reflection coefficient parameter was measured (S11).

As shown in Fig. 19 there is a good agreement between simulated and measured results. Some discrepancies can be seen between the simulated and measured results, which may occur because the effect of the SMA connector, the fabrication imperfections and the measurement calibration while using the VNA.

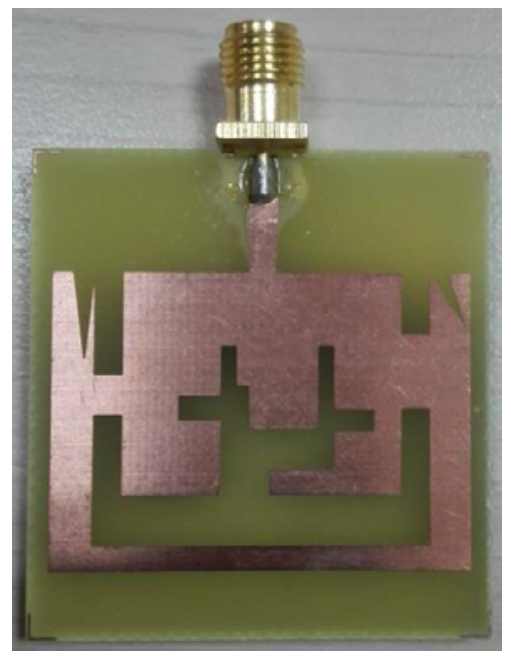

Fig. 18 Top View Fabricated Microstrip Antenna

The antenna resonate at $2.8 \mathrm{GHz}$ (between 2.794 to $2.846 \mathrm{GHz}$ ), at $3.1 \mathrm{GHz}$ (between 3.145 to $3.196 \mathrm{GHz}$ ), at $3.6 \mathrm{GHz}$ (between 3.56 to $3.3 .644 \mathrm{GHz}$ ), at $4.7 \mathrm{GHz}$ (between 4.684 to $4.772 \mathrm{GHz}$ ) and at $5.4 \mathrm{GHz}$ (between 5.423 to $5.526 \mathrm{GHz}$ ) for WiMAX/WLAN applications.

In this design, if the slots are absent, the antenna will only have one major current path on each of the patch elements. However, in the presence of the current slots, the current path on each of the patch elements is disturbed and perturbed, hence creating the penta-band operation.

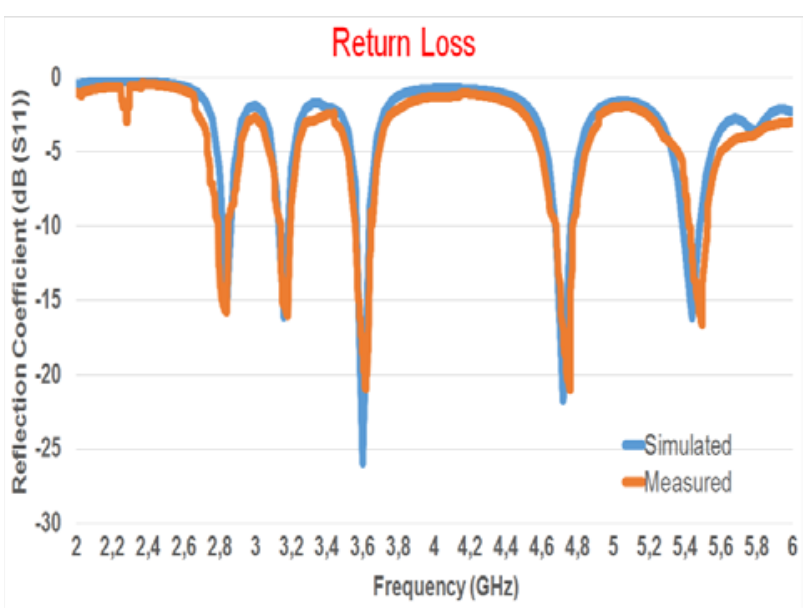

Fig. 19 Simulated vs Measured Results

\section{Conclusions}

In the current work, a penta-band antenna with two modified U slots is designed, simulated and fabricated without modifying the ground plane, keeping a low profile $(1.2 \mathrm{~mm})$ and using a low cost substrate (FR4). The antenna parameters were simulated using HFSS software and measurements were developed with a Vector Network Analyzer for impedance matching. Simulated and measured results shows that the antenna resonate at $2.8 \mathrm{GHz}$ (between 2.794 to $2.846 \mathrm{GHz}$ ), at $3.1 \mathrm{GHz}$ (between 3.145 to $3.196 \mathrm{GHz}$ ), at $3.6 \mathrm{GHz}$ (between 3.56 to $3.3 .644 \mathrm{GHz}$ ), at $4.7 \mathrm{GHz}$ (between 4.684 to $4.772 \mathrm{GHz}$ ) and at $5.4 \mathrm{GHz}$ (between 5.423 to $5.526 \mathrm{GHz}$ ) for WiMAX/WLAN applications.

Slots played a key role as they control the resonance frequencies. Adjusting accordingly width length and position modified current distribution concentrated at slots and then modifying the resonance frequencies, facilitating the antenna resonate at other three frequencies.

Therefore, the designed antenna can work within WiMAX and WLAN compliance applications. Current antenna may work as a reference for future works related to optimization and improvement of slotted planar patch antennae looking to miniaturize current dimensions, improve gain or modifying other desired characteristic aiming to improve it

\section{References}

[1] G. Kumar and K. P. Ray, Broadband Microstrip Antenna. Artech House, (2003).

[2] T. Milligan, Modern Antenna Design, 2nd Ed. Jhon Wiley \& Sons, Innc., (2005).

[3] C. Balanis, Antenna Theory. Analysis and Design. John Wwiley \& Ssons, INC., (2005).

[4] A. Lozada and S. Donglin, "Microstrip Antenna for Satellite Communications," in International Symposium on Antennas, Propagation and EM Theory, (2008), pp. $1-3$.

[5] S. Sultan, S. Imran, C. Xiaodong, and P. Clive, "Compact and Printed Multiband Antennas for 2G/3G/4G Smartphones," in International Symposium 
on Antennas and Propagation \& USNC/URSI National Radio Science Meeting, (2015), pp. 1138-1139.

[6] M. A. Ennasar, I. Aznabet, M. Essaaidi, and M. Group, "A Compact Modified S-Shaped RFID Tag Antenna for Metallic Applications," in IEEE 15th Mediterranean Microwave Symposium (MMS), (2015), pp. 8-10.

[7] S. Ha and C. W. Jung, "Single patch beam steering antenna with U-slot for wearable fabric applications," in IEEE International Symposium on Antennas and Propagation (APSURSI), (2011), pp. 1560-1562.

[8] U. Shameem, M. Ur-rehman, Q. H. Abbasi, and K. Qaraqe, "A Low Profile Penta-band Antenna For Portable Devices," in International Workshop on Antenna Technology (iWAT), (2016), pp. 174-177.

[9] L. Peng, C. L. Ruan, and J. Xiong, "Compact EBG for multi-band applications," IEEE Trans. Antennas Propag., vol. 60, no. 9, pp. 4440-4444, (2012).

[10] L. X. Truong and Tran Minh Tuan, "Design A Microstrip Antenna With Defected Ground Structure," in 2015 International Conference on Advanced Technologies for Communications (ATC) Design, (2015), pp. 160-163.

[11] M. Borhani, P. Rezaei, and A. Valizade, "Design of A Reconfigurable Miniaturized Microstrip Antenna for Switchable Multiband Systems," IEEE Antennas Wirel. Propag. Lett., vol. 1225, no. c, pp. 1-1, (2015).

[12] M. Chang and W. Weng, "A Printed Multi-band Slot Antenna for LTE / WLAN Applications," in IEEE International Symposium on Antennas and Propagation \& USNC/URSI National Radio Science Meeting, (2015), pp. 1144-1145.

[13] M. Nirmen and I. H. Ehab K., "Tri-Band Microstrip Antenna with L-Shaped Slots for Bluetooth / WLAN / WiMAX Applications," 33 rd Natl. Radio Sci. Conf. (NRSC (2016)), no. Nrsc, pp. 73-80, (2016).

[14] A. K. Gautam, L. Kumar, and B. K. Kanaujia, "Design of Compact F-Shaped Slot Triple-Band Antenna for WLAN / WiMAX Applications," Trans. Antennas Propag., vol. 64, no. 3, pp. 1101-1105, (2016).

[15] Y. Zimu, Z. Hou, Z. Leiming, and W. An, “A Ushaped Slot Antenna for WLAN and WiMAX Applications," in 7th Asia Pacific International Symposium on Electromagnetic Compatibility, (2016), pp. 152-154.

[16] C. Bhan, A. K. Dwivedi, B. Mishra, and A. Kumar, "Quad Bands U-Shaped Slot Loaded Probe Fed Microstrip Patch Antenna," (2015) Second Int. Conf. Adv. Comput. Commun. Eng., pp. 409-412, (2015).

[17] Q. Wu, L. Shi, and G. Zhao, "Design of a Ku-band broadband U-slot microstrip antenna," in IEEE International Conference on Microwave Technology and Computational Electromagnetics, (2013), pp. 212-215.

[18] H. F. Abutarboush and A. Shamim, "Paper-based inkjet-printed tri-band U-slot monopole antenna for wireless applications," IEEE Antennas Wirel. Propag. Lett., vol. 11, pp. 1234-1237, (2012).

[19] S. Bansal and J. B. Sharma, "Hexa Band Asymmetrical U-Slot Microstrip Patch Antenna for Wireless Applications," in Annual IEEE India Conference (INDICON), (2015), pp. 25-28.
[20] R. Tej and C. Brajlata, "Single Layer Dual band Microstrip Patch Antenna using Probe Feed," Int. J. Comput. Appl., vol. 92, no. 12, pp. 1-5, 2014.

[21] H. F. AbuTarboush, H. S. Al-Raweshidy, and R. Nilavalan, "Triple Band Double U-Slots Patch Antenna for WiMAX Mobile Applications," (2008) 14Th AsiaPacific Conf. Commun. (Apcc), Vols 1 2, pp. 140-142, (2008).

[22] T. Alam, M. R. I. Faruque, and M. T. Islam, "Probe-fed rectangular patch antenna for wireless communication," (2015) Int. Conf. Netw. Syst. Secur., pp. 1-4, (2015).

[23] R. Jothi Chitra, A. Suganya, and V. Nagarajan, "Enhanced gain of double U-slot micro strip patch antenna array for WiMAX application," (2012) Int. Conf. Commun. Signal Process. ICCSP-(2012), pp. 141144, (2012). 